\title{
Tackling COVID-19 infection through complement-targeted immunotherapy
}

\author{
Sonata Jodele ${ }^{1}$ and Joerg (GUEST EDITOR) Koehl² \\ ${ }^{1}$ Cincinnati Children's Hospital Medical Center \\ ${ }^{2}$ Universität zu Lübeck Sektion Medizin
}

May 6, 2020

\begin{abstract}
The complement system is an ancient part of innate immunity sensing highly pathogenic coronaviruses by Mannan-binding lectin resulting in lectin pathway-activation and subsequent generation of the anaphylatoxins (AT) C3a and C5a as important effector molecules. Complement deposition in endothelial cells and high blood C5a serum levels have been reported in COVID19 patients with severe illness, suggesting vigorous complement activation leading to systemic thrombotic microangiopathy (TMA). Strikingly, SARS-CoV-2-infected African Americans suffer from high mortality. Complement regulator gene variants prevalent in African Americans have been associated with a higher risk for severe TMA and multi-organ injury. These findings allow us to apply our knowledge from other complement-mediated diseases to COVID-19 infection to better understand severe disease pathogenesis. Here we will discuss the multiple aspects of complement activation, regulation, crosstalk with other parts of the immune system and the options to target complement in COVID-19 patients to halt disease progression and death.
\end{abstract}

\section{Introduction}

The novel coronavirus, Severe Acute Respiratory Syndrome (SARS)-Coronavirus (CoV)-2 first identified in 2019 in Wuhan region, China resulted in worldwide COVID-19 pandemic uniting clinicians and researchers from many countries desperately searching for effective clinical interventions. The United States of America are one of the countries with highest incidence of COVID-19 with 1.042.874 cases diagnoses and 61.123 of total deaths by April 30, 2020 (University, 2020). SARS-CoV-2 belongs to the family of Coronaviridae, positivesense single stranded RNA viruses that frequently cause mild respiratory infections in humans. During the past two decades two endemics with SARS-CoV in 2003 and Middle East Respiratory Syndrome (MERS)$\mathrm{CoV}$ in 2012 occurred with estimated case-fatalities of $14-15 \%$ or even $35 \%$ in case of MERS-CoV. (Gao et al., 2020). COVID-19 disease has wide range of clinical presentations from asymptomatic cases to severe respiratory involvement acutely progressing to Acute Respiratory Distress Syndrome (ARDS) and multiorgan failure. A growing body of literature on COVID-19 reports atypical presentation of ARDS (Gattinoni, Coppola, Cressoni, Busana, Rossi \& Chiumello, 2020), a result of host immune system overactivation and fatal hypercytokinemia, leading to tissue injury and multi-organ failure, which may be attributed to an overactivated complement system (Gao et al., 2020; Lipworth, Chan, Lipworth \& RuiWen Kuo, 2020; Magro et al., 2020).

\section{Complement activation and function in highly pathogenic coronaviruses}

The complement system senses invading pathogens as well as environmental or self-derived antigens by pattern recognition molecules of the canonical classical and lectin pathways (CP and LP). This function is critical to our sustained health and survival. It results in a cascade of proteolytic events leading to the cleavage of $\mathrm{C} 3$ into the anaphylatoxin (AT) C3a and the opsonin C3b by pathway-specific canonical C3 convertases. Consecutively, such C3 convertases build the framework for C5 convertases that cleave 
C5 into the AT C5a and C5b. In addition to classical and lectin pathway activation, the thioester in C3 can be directly activated by any nucleophilic attack leading to the activation of the so-called alternative pathway (AP), driving strong cleavage of C3 and C5. Eventually, C5b forms the nucleus for non-proteolytic terminal pathway activation leading to the formation of the soluble (s)C5b-9 complex in the circulation of the poring-forming membrane attack complex (MAC) on cell surfaces which can drive cell lysis (Figure 1).

Similar to SARS-CoV, the genome of SARS-CoV-2 encodes for several structural and non-structural proteins including the spike (S) protein which is critical for cell entry through engagement of angiotensin-converting enzyme 2 (ACE2) and the employment of the cellular serine protease TMPRSS2 for S protein priming (Hoffmann et al., 2020). The S protein of SARS-CoV is sensed by Mannan-binding lectin (MBL) suggesting that complement activation in SARS-CoV infection is driven by activation of the LP of complement (Ip et al., 2005; Zhou et al., 2010). In addition to $\mathrm{S}$ protein sensing by MBL, nucleocapsid (N) protein interaction with MASP-2, the key protease of the LP activation has been described for SARS-CoV, MERS-CoV and SARS-CoV-2 that strongly affects LP activation (Figure 1) (Gao et al 2020 medRxiv preprint doi: doi.org/10.1101/2020.03.29.20041962). In addition to MBL/MASP-2-driven activation of the LP, complement might be activated by the classical pathway $(\mathrm{CP})$ through virus-neutralizing IgG antibodies (Figure 1). In COVID-19 patients, seroconversion occurred similar or slightly earlier than in SARS-CoV patients. Around 50\% of COVID-19 patient showed seroconversion on day 7 after development of symptoms (Wolfel et al., 2020). Of note, in SARS-CoV-infected patients, the appearance of anti-viral IgG coincides with onset of ARDS in $80 \%$ of patients (Peiris et al., 2003).

The small cleavage fragments of C3 and C5, the ATs C3a and C5a are important effector molecules that attract, activate and regulate innate and adaptive immune cells (Laumonnier, Karsten \& Kohl, 2017). C5a exerts powerful proinflammatory properties through activation of such proinflammatory cells. For example, C5a induces the expression of IL-1 $\beta$ and IL- 8 in mononuclear cells and enhances the release of IL- 6 and TNF- $\alpha$ (Schindler, Gelfand \& Dinarello, 1990). ARDS is mediated by the recruitment and activation of inflammatory cells such as neutrophils, eosinophils, monocytes and T lymphocytes (Meliopoulos et al., 2014). Similar to SARS-CoV-2, MERS-CoV or SARS-CoV as well as other respiratory virus such as the Influenza virus can be associated with a similar rapid progression to ARDS. MERS-CoV drives the production of inflammatory and chemotactic cytokines as well as chemokines such as CXCL-10, CCL2, IL-8, IL-12 and IFN- $\gamma$, which can cause severe lung damage (Jiang et al., 2019; Jiang et al., 2018). High levels of C5a have been also found in bronchoalveolar lavage fluid (BAL) of individuals affected by viral-mediated acute lung injury (ALI) but not in BAL from recovered patients with ARDS (Wang, Xiao, Guo, Li \& Shen, 2015). Further, the histopathological changes in the lung from patients infected with influenza virus mimic those infected with SARS-CoV (Meliopoulos et al., 2014). The influenza virus is highly pathogenic replicating in the lower respiratory tract. It drives pulmonary complement activation leading to high levels of C5a in BAL and serum (Ohta, Torii, Imai, Kimura, Okada \& Ito, 2011). In experimental, highly pathogenic avian influenza H5N1 infection, C5a contributes ALI in mice. Further, inhibition of C5a by a C5a-specific mAb alleviated such lung injury in H5N1 virus infection in this model (Sun et al., 2013). Similarly, anti-C5a $\mathrm{mAb}$ treatment improved the outcome of H7N9 virus infection in African green monkeys; in particular such treatment attenuated ALI and systemic inflammation, i.e. the "cytokine storm"(Sun et al., 2015). Maybe even more important, blockade of the C5a/C5aR1 axis reduced lung and spleen tissue damage and reduced inflammatory responses in experimental MERS-CoV infection. Also, it decreased viral replication in the lung. Recently, it was further shown that C3-deficient mice infected with SARS-CoV suffered from less respiratory dysfunction associated with less recruitment of neutrophils and inflammatory monocytes in the lungs and less cytokine and chemokine levels (Gralinski et al., 2018).

Taken together, the available data suggest that complement is activated in highly pathogenic coronavirus infection and contributes to the development of ALI that has been observed in experimental models and in patients. In the following sections, we will discuss complement-mediated microvascular injury in COVID-19 patients, complement genetics as a potential clue to race differences in COVID-19 severity, options to target complement in COVID-19 patients with atypical ARDS and TMA and potential intersection of complement with other inflammatory pathways, offering the opportunity for concurrent interventions. 


\section{Complement-associated microvascular injury in severely ill COVID-19 patients}

It is currently unknown, why some patients with novel coronavirus SARS-CoV-2 infection develop mild symptoms while others progress to severe COVID-19 illness and multisystem organ failure with extremely high mortality rates. It is also unknown, why some patient populations, especially African Americans, are at higher risk to develop severe complications in response to SARS-CoV-2 infection. Recent autopsy data from New Orleans in 4 African American patients who succumbed to COVID-19 infection (Fox, Akmatbekov, Harbert, Li, Brown \& Vander Heide, 2020) demonstrated diffuse alveolar damage and TMA associated with foci of alveolar hemorrhage in the lungs. One of the cases had extensive fibrin with degenerated neutrophils within the alveoli possibly representing neutrophil extracellular traps (NETs). RNA imaging in available samples demonstrated multinucleated cells within alveolar spaces with abundant RNA, likely representing virally infected cells similar to previously reported in post-mortem case from China (Xu et al., 2020). The most significant gross cardiac finding was cardiomegaly with right ventricular dilatation in all patients without evidence of myocarditis. Elevated B-type natriuretic peptide associated with right ventricular dilatation was documented at least in one case. The authors hypothesized that these finding might be consistent with recent observation by Chen et al hypothesizing that pericytes may be infected by the SARS-CoV-2 virus and cause capillary endothelial cell microvascular dysfunction which may cause individual cardiac cell necrosis (Chen, Li, Chen, Feng \& Xiong, 2020) There were no documented secondary bacterial of fungal infections, although all these patients received antimicrobials during critical illness. Based on these findings, the authors concluded that effective therapy for these patients should include targeted therapy for TMA in addition to virus directed therapies.

Further studies showed complement-associated microvascular injury and thrombosis in critically ill SARSCoV-2-infected patients. They found extensive deposits of the terminal complement complex C5b-9, C4d and MASP2 in small vessels of affected organs (Fox, Akmatbekov, Harbert, Li, Brown \& Vander Heide, 2020; Magro et al., 2020). Co-localization of complement components C5b-9 and C4 with SARS-CoV-2 spike glycoprotein indicated viral invasion of vascular endothelial cells that had been also demonstrated by reports of electron microscopy showing viral inclusion structures in vascular endothelial cells in lungs, heart, kidney, gastrointestinal tract and the skin (Magro et al., 2020). A recent study from Wuhan identified strong staining for MBL, MASP-2, C4a C3b and C5b-9 in type I and type II alveolar epithelia cells, inflammatory cells, pneumocytes, and even in exudates in alveolar spaces with necrotic cell debris (Gao et al., 2020).

Pulmonary abnormalities in severely affected patients are largely restricted to the alveolar capillaries, presenting as TMA with some evidence of viral cytopathic changes in alveolar lining. It is known that the virus uses ACE2 receptor expressed by pneumocytes in the epithelial alveolar lining to infect the host, thereby most commonly causing lung injury, but ACE2 receptors are also widely expressed on vascular endothelial cells, so multiple organs can be affected (Ou et al., 2020). There is potential interaction of complement with coagulation pathways resulting in acutely progressive microthrombosis with fibrin deposition and highly elevated D-dimers (Figure 2). Regardless of the originating insult leading to TMA, complement-mediated vascular endothelial injury may respond to complement-modulating therapies and offers the opportunity to adopt current knowledge from other TMAs to COVID-19.

\section{Complement genetics as a potential clue to race differences in COVID-10 severity}

One of the current obstacles in COVID-19 infection is the racial difference in patients developing severe illness. As outlined above, highly pathogenic coronaviruses are recognized by MBL. Several polymorphisms have been described for MBL in exon 1 at codon positions 52, 54, and 57 (Steffensen, Thiel, Varming, Jersild \& Jensenius, 2000). The A allele can be distinguished from R52C, G54D, and G57E polymorphisms described as D, B and C alleles (Garred, Larsen, Seyfarth, Fujita \& Madsen, 2006). These polymorphisms in exon 1 together with those in the promoter region profoundly affect circulating levels of MBL (Madsen et al., 1995). Importantly, MBL polymorphisms have been associated with fatal outcome in patients with sepsis, SIRS (Garred, J, Quist, Taaning \& Madsen, 2003; Hellemann et al., 2007) and ARDS (Gong, Zhou, Williams, Thompson, Pothier \& Christiani, 2007). Also, some (Ip et al., 2005; Tu et al., 2015; Zhang et al., 2005) but not all (Yuan et al., 2005) studies found a significant association between MBL codon variant in 
exon 1 and the risk of severe SARS-CoV infection. Thus, polymorphisms in exon 1 and/or the promoter region of MBL may define the extent of complement activation in COVID-19 patients (Figure 3). In support of this view, strong differences have been observed between haplotype frequencies in Asians, Caucasians, Hispanic and African Americans(Garred, Larsen, Seyfarth, Fujita \& Madsen, 2006). Intriguingly, the G54D polymorphism is extremely rare in West Africa but can be found at higher frequencies in Caucasian, Asians and indigenous South Americans, respectively. In contrast, the $\mathrm{C}$ allele is more frequent in sub-Saharan Africa but rare among Caucasians. The D allele is largely restricted to North Africans and Caucasians. It has been speculated that environmental pressures such as a tuberculosis infections could account for the fact that almost $60 \%$ of the sub-Saharan population contains the C allele (Bernig, Taylor, Foster, Staats, Yeager $\&$ Chanock, 2004). In support, a protective association was found between the $\mathrm{C}$ allele and a tuberculosis infection with $M$. africanum (Thye et al., 2011). Thus, racial differences in MBL-mediated complement activation may account for different complement activation in COVID-19.

In addition to MBL, complement genetics studies in hematopoietic stem cell transplantation (HSCT) recipients provide evidence of racial disparities in predisposition to develop TMA and risk of mortality under intense stress like the transplantation process and may serve as a hypothesis for higher mortality seen in African Americans with COVID-19 infection. A previous large HSCT registry report described inferior survival in African Americans after unrelated donor HSCT, but it was unable to attribute reduced outcomes to risk factors such as HLA-matching and socioeconomic status (Baker et al., 2009). A prospective study examining genetic predisposition for transplant associated thrombotic microangiopathy (TA-TMA) in HSCT recipients demonstrated that $65 \%$ of patients with TA-TMA had genetic variants in at least one complement gene as compared with $9 \%$ of patients without TA-TMA $(\mathrm{P}<.0001)$ using a hypothesis driven 17 gene panel including the complement factors C3, Factor B (FB), C5, FP, FD, FI, FH, FHR1, FHR3, FHR 4, FHR5, $C D 55, C D 59, C D 46, C 4 B P A$. (Jodele et al., 2016c). Importantly, many of the complement genes belong to complement regulators that either control the amplification of the cascade at the level of C3, i.e. FH, CD55, CD46, FI or fuel the amplification loop (FB, FP, FD).

Complement gene variants were increased in patients of all races with TA-TMA, but African Americans had more variants than Caucasians. While the $F D$ variant (c.357116C.A) was detected only in African American patients with TMA, it was mainly the number of variants occurring in individuals with TATMA and not a particular gene variant that was significantly associated with TMA and disease severity. Variants in [?] 3 genes were identified only in African Americans with TA-TMA and were associated with very high mortality after HSCT (71\%) associated with strong complement activation (Jodele et al., 2014). The finding of multiple variants occurring at high frequency in persons of African descent associated with strong complement activation suggests a selective benefit of strong complement activation in Africans as a defense mechanism to combat infectious pathogens like Neisseria meningitides, a prevalent cause of mortality in endemic areas of Africa (African meningitis belt). Clearly, SNPs in C3 (Adriani et al., 2013) and FH have been associated with susceptibility (Davila et al., 2010) to this pathogen. The homeostasis of complement is controlled by an equilibrium between activation and control. Dysregulation of complement activation at the level of C3 through loss- or gain-of function mutations of regulators or gain of function mutations in activator proteins results in uncontrolled complement activation and inflammation as seen in many inflammatory conditions including HSCT-TMA (Figure 3). The combination of several complement gene polymorphisms, in particular in $C 3, F H$ and $F B$ has been found to determine systemic complement activity and the susceptibility to AP-driven diseases (Heurich et al., 2011; Paun et al., 2016). Thus, the available data from HSCT-TMA suggest that African American with multiple variations in complement genes react with stronger complement activation in response to infection with highly pathogenic coronaviruses including SARS-COV-2 resulting in uncontrolled pulmonary tissue inflammation and complement deposition in several organs.

In support of this view we found at least one complement gene variant in $32 \%$ of well children when we investigated 50 African Americans and 50 Caucasians. The frequency of gene variants differed markedly by race with $50 \%$ of African American children having at least one gene variant, compared to only $14 \%$ of Caucasian children although the overall variant frequencies were lower than those we have reported in HSCT recipients(Jodele, Zhang, Dandoy, Myers, Lane \& Davies, 2017). 
Taken together, it will be important to examine genetic variants of complement proteins in patients infected with SARS-CoV-2 and to correlate such variants with disease severity. Such data might aid prediction of the risk to develop virus-associated TMA.

\section{Complement therapy in COVID-19 patients}

Multiple teams around the world are striving to identify effective therapies for COVID-19. SARS-CoV-2 preventive measures aiming at developing an effective vaccine as well as therapeutic approaches including different strategies of anti-viral medications or virus-specific T cells (VST) have high potential for being effective in the future. The clinical appearance of severely-ill COVID-19 patients with atypical ARDS and TMA and the association of this clinical phenotype with marked complement activation in the circulation and in the lung (Gao et al., 2020; Lipworth, Chan, Lipworth \& RuiWen Kuo, 2020; Magro et al., 2020) suggests that complement may also serve as a target in COVID-19 patients. Encouraging first data have been reported for severely ill COVID-19 subjects, who were either treated with a C5- or a C5a-blocking antibody (Diurno et al., 2020; Gao et al., 2020). Both approaches resulted in quick clinical improvement and will be further outlined below. In this section we will discuss potential clinical strategies that we can adopt now from other disciplines to prevent acute mortality from atypical ARDS and other organ failure in COVID-19-affected individuals with a particular focus on complement-mediated TMA.

\section{Complement pathways as potential targets}

The available data suggest that the LP and the CP are the two major complement pathways activated in response to SARS-CoV-2. MBL, collectin 10 and -11 as well as the ficolins 1-3 function as soluble sensors of the LP (Garred et al., 2016). They interact with the serine protases MASP1 and MASP2 that act in concert to cleave $\mathrm{C} 4$ and $\mathrm{C} 2$ and form the $\mathrm{C} 3$ convertase $\mathrm{C} 4 \mathrm{~b} 2 \mathrm{~b}$ which proteolytically cleave $\mathrm{C} 3$ into $\mathrm{C} 3 \mathrm{a}$ and $\mathrm{C} 3 \mathrm{~b}$ (Figure 1). MBL comprises multiple carbohydrate recognition domains that can bind to the high-mannose structure of the SARS-CoV S protein (Ip et al., 2005). In particular, the N-linked glycosylation site, N330, on the S protein seems to be critical for MBL interaction. Further, MBL directly inhibited SARS-CoVmediated infection in vitro (Zhou et al., 2010). In addition to the $\mathrm{S}$ protein, a recent report uncovered the interaction of LP MASP-2 with a highly conserved motif in the N protein of SARS-CoV, SARS-CoV-2 and MERS-CoV. Intriguingly, this interaction not only potentiated MASP-2-driven activation of the LP but aggravated LPS-induced pneumonia in a MASP-2-dependent way (Gao et al., 2020). Given that the $\mathrm{N}$-protein is one of the most abundant structural proteins in the serum of patients infected by SARS-CoV (Che et al., 2004; Chen et al., 2005; Guan, Chen, Foo, Tan, Goh \& Wee, 2004) these data indicate that the N protein-mediated interaction with MASP-2 could serve as an important amplifier of LP activation in highly pathogenic coronavirus infection. Thus, the available data point toward the LP as an important target in these virus infections.

$\mathrm{C} 1 \mathrm{q}$ is the sensor molecule of the $\mathrm{CP}$ that recognizes multiple conserved molecular patterns including IgM or IgG hexamer molecules that have bound to their cognate antigen. Similar to MASP-1 and MASP-2, the serine proteases $\mathrm{C} 1 \mathrm{r}$ and $\mathrm{C} 1 \mathrm{~s}$ form a complex with IgG/IgM-bound $\mathrm{C} 1 \mathrm{q}$ to cleave $\mathrm{C} 4$ and $\mathrm{C} 2$ and generate the C4b2b convertase eventually cleaving C3 into C3a and C3b (Figure 1). Within the first week after symptoms, COVID-19 infection results in the production of $\mathrm{S}$ protein-specific IgG/IgM antibodies as a target structure for C1q (Wolfel et al., 2020). A recent study from Wuhan shows that during the first 5 days after clinical onset, already $30-40 \%$ of the infected individuals have generated IgM or IgG antibodies directed against the $\mathrm{S}$ or $\mathrm{N}$ proteins of SARS-CoV-2, with a slightly higher frequency of antibodies against the $\mathrm{S}$ protein (Liu et al., 2020). After 5 weeks, all of the 214 tested patients showed IgG seroconversion. These data suggest that the seroconversion is somewhat quicker than what has been observed with SARS-CoV (Peiris et al., 2003). Taken together, CP activation by IgM and IgG antibodies directed against the $\mathrm{S}$ and $\mathrm{N}$ proteins of SARS-CoV and SARS-CoV-2 serves as second mechanism of complement activation in addition to the initial virus sensing by the MBL and LP activation (Figure 1).

The $\mathrm{C} 3$ convertase $\mathrm{C} 4 \mathrm{~b} 2 \mathrm{~b}$, which is assembled in response to LP and CP activation generates the AT C3a from $\mathrm{C} 3$, which can degranulate basophils and mast cells leading to histamine release through activation of 
its cognate C3aR (el-Lati, Dahinden \& Church, 1994; Kretzschmar et al., 1993). C3aR expression is triggered in neutrophils upon LPS exposure and contributes to NETosis (Guglietta et al., 2016). Further, C3a induces aggregation and serotonin release from platelets, regulates secretion of IL- 6 and TNF- $\alpha$ from B-cells and monocytes and leads to the production of IL-8 by an epithelial cell line (Fischer \& Hugli, 1997; Fischer, Jagels \& Hugli, 1999; Fukuoka \& Hugli, 1988). Intracellularly, C3a plays an important role in activating the NLRP3-inflammasome in human monocytes (Asgari et al., 2013). Taken together, C3a can mediate a strong pro-inflammatory environment. The $\mathrm{C} 3$ convertase also serves as the nucleus of the C5 convertase when C3b molecules form a complex with C4b2b resulting in C4b2b3b, the C5 convertase of the LP and the CP which cleaves C5 into the AT C5a and C5b (Figure 1) (Ekdahl et al., 2019). Similar to C3a and in concert with C3a, C5a can drive a strong pro-inflammatory environment through its strong chemotactic properties on neutrophils, monocytes, eosinophils, basophils, mast cell and dendritic cells (DC) and it strong potency to activate such cells to release ROS, lysosomal enzymes as well as pro-inflammatory cytokines such as IL-1 $\beta$, TNF- $\alpha$, IL-6 and chemokines of the CC and CXC families (Figure 2). C5a also drives the activation and differentiation of $\mathrm{T}$ cells through DC maturation downstream of C5aR1 (Antoniou et al., 2020; Weaver et al., 2010). Also, C5a controls histamine-induced increase in vasopermeability (Kordowski et al., 2019) and drives the production of metabolites of the arachidonic acid lipoxgenase and cyclooxygenase pathways resulting in increased production of leukotriene B4 (LTB4) or prostaglandine E2, both of which increase vasopermeability (Karasu, Nilsson, Kohl, Lambris \& Huber-Lang, 2019; Klos, Tenner, Johswich, Ager, Reis \& Kohl, 2009).

Importantly, such increased vasopermeability of the alveolar-capillary interface, massive neutrophil recruitment associated with tremendous production of proinflammatory cytokines and chemokines including IL-1 $\beta$, IL-6, IFN- $\gamma$, IL-8, CXCL10 and CCL2 leading to the development of ALI/ARDS has been observed in infections with highly pathogenic respiratory viruses including H5N1 influenza, SARS-CoV and MERS-CoV (Jiang et al., 2019; Jiang et al., 2018). In experimental models as well as in patients infected with influenza (Ohta, Torii, Imai, Kimura, Okada \& Ito, 2011), SARS-CoV (Gralinski et al., 2018), MERS-CoV (Jiang et al., 2018) or SARS-CoV-2 (Gao et al., 2020; Magro et al., 2020) increased blood levels and/or lung deposits of complement activation products have been described.

Taken together, the picture emerges that highly pathogenic coronaviruses activate complement by the LP and CP. This activation drives the generation of huge amounts of the highly proinflammatory cleavage products $\mathrm{C} 3 \mathrm{a}$ and $\mathrm{C} 5 \mathrm{a}$, when complement activation is not sufficiently controlled by complement regulator proteins (Figure 3). Further, TMA results in C3 and C5 cleavage of by non-canonical pathways through serine proteases located in the intracellular space of in the vasculature that exert promiscuous enzyme activity (Figure 2) (Ekdahl et al., 2016). Below, we will discuss strategies to prevent the initiation of LP and $\mathrm{CP}$, to attenuate convertase-mediated amplification and to inhibit the effector functions of C5a/C5aR1 axis activation.

\section{Inhibition of lectin pathway and classical pathway initiation}

\section{Targeting the lectin pathway}

Within the LP, either the sensor molecules MBL, the ficolins 1-3, the collectins 10 and 11 or the serine proteases MASP1 and MASP-2 could serve as potential targets. At this point, no strategies have been developed to target the sensor molecules. However, Omeros has developed the MASP-2 targeting human mAB narsoplimab (OMS721) that is currently used in phase III trials for HSCT-TMA, IgA nephropathy and aHUS and in a phase II trial for lupus and other renal diseases (Medicine). For TMA, the FDA has granted narsoplimab breakthrough designation in patients with persistent TMA as well as orphan drug designation for the inhibition of complement-mediated TMAs and the treatment of HSCT-TMA. Given that narsoplimab is already in clinical trials for diseases in which TMA is a critical disease driver, it might be worth to consider this approach for severe cases of COVID-19 infection (Figure 1).

In addition to MASP-2, a C2-blocking antibody (PRO-02) has been developed by Prothix/Broteio to inhibit the formation of the $\mathrm{C} 4 \mathrm{~b} 2 \mathrm{~b}$ convertase of the LP and the $\mathrm{CP}$ and is tested as potential therapeutic approach 
for ischemia reperfusion injury-mediated disorders and autoimmune diseases (Borosss, Yildiz, Simons, Boon \& Hack, 2016).

\section{Targeting the classical pathway}

Potential targets specific for the $\mathrm{CP}$ are either the pattern recognition molecule $\mathrm{C} 1 \mathrm{q}$ or the serine proteases C1r and C1s. Antibodies against C1q have been generated by Annexon, either as a complete mAb (ANX005) or as a Fab fragment (ANX009) both of which have completed Phase 1b trials for Guillain-Barre Syndrome (GBS) or glaucoma showing full inhibition of the CP activation. The FDA has granted ANX005 Fast Track and Orphan drug designation for the treatment of GBS. Antibodies are also available that are directed against C1s. Based on the mouse antibody TNT003(Shi et al., 2014) the Sanofi subsidiary Bioverativ has developed (a Sanofi company) the humanized antibody sutimlimab (TNT009) that is currently tested in a phase III trial for cold agglutinin disease (CAD), a subtype of autoimmune hemolytic anemia (AIHA) and in a phase I trial for idiopathic thrombocytopenic purpura. In a small cohort of 10 patients suffering from CAD, sutimlimab was found to be safe, well-tolerated and rapidly stopped CP-mediated hemolysis (Jager et al., 2019). In December 2019, Sanofi has reported first results from the phase III trial showing that sutimlimab inhibited hemolysis and improved anemia and fatigue in CAD patients shortly after treatment(Medicine, 2019). Finally, plasma protease $\mathrm{C} 1$ inhibitor (C1INH) controls the activity of $\mathrm{C} 1 \mathrm{~s}$ and has been on the market for more than 20 years for the treatment of hereditary angioedema. The problem with C1INH is that it is not only targeting C1s but also proteases of the coagulation-, kinin- and fibrinolysis-pathways (Levi, Cohn \& Zeerleder, 2019). Thus, for selective and tailored targeting of the CP C1INH is not on option.

In summary, antibodies are available that specifically target the LP or the CP and are already in Phase III trials. Given that both virus-driven LP and adaptive immune response-mediated CP activation by virusspecific IgG and IgM antibodies will activate the complement system (Figure 1), it might be insufficient to target the LP only.

\section{Targeting complement amplification at the level of C3}

As aptly put by the Lambris lab, C3 serves as the "swiss army-knife" of the complement proteins. C3b generated from $\mathrm{C} 3$ in response to $\mathrm{CP}$, LP or alternative pathway (AP) activation can amplify the initial complement activation by either pathway, when it forms the C3bB complex that can be cleaved by the serine protease factor D (FD) resulting in the self-amplifying C3bBb convertase (Ricklin, Reis, Mastellos, Gros \& Lambris, 2016). This amplification loop will feed the cleavage of many molecules of C3 when not appropriately controlled by complement regulator proteins (Figures 1 and 3). The available data suggest that such control by complement inhibitors of the regulator of complement activation (RCA) family is disturbed in patients developing ARDS and TMA following infection with highly pathogenic coronaviruses, in particular in African Americans (Figure 3). All of these RCA proteins harbor complement control protein domains. Some of them are membrane-bound such as complement receptor 1 (CR1/CD35) membrane cofactor protein (MCP/CD46), decay-accelerating factor (DAF/CD55), whereas other are found in the circulation (FH, C4 binding protein $(\mathrm{C} 4 \mathrm{BP})$ ). Mechanistically, the RCA proteins either destabilize the $\mathrm{C} 3$ convertases or serve as co-factors for Factor I (FI)-mediated degradation of C3b to iC3b and C3dg, which no longer contribute to the formation of the amplification loop. As implied by the name, CD55 accelerates the decay of the convertase, whereas CD46 mediates degradation of C3b. CR1, FH and C4BP exert both functions.

Several compounds have been developed that target the C3 convertase either by targeting molecules that are critical for assembly (FB, FD, MASP-3) or the destabilization of the convertase complex and degradation of C3b (CR1, FH). These compound have recently been discussed in detail in two excellent reviews (Mastellos, Ricklin \& Lambris, 2019; Ricklin, Mastellos, Reis \& Lambris, 2018). Prima vista, FD is an attractive target in COVID-19 infection, given that the proteolytic cleavage of FB by this serine protease is a crucial step to ignite the amplification loop. Also, plasma levels are relatively low, although high plasma turnover might pose a challenge. Thus, it is not surprising that small molecule inhibitors (Novartis, Achillion) and FDantibodies (Genentech) have been generated and tested in several clinical trials. Also, a MASP-3-specific antibody (OMS906) has been developed by Omeros to block the conversion of por-FD to FD (Dobo et al., 
2016; Hayashi et al., 2019). However, several other serine proteases can cleave C3 including elastase from neutrophils or proteases of the coagulation, the kinin and the fibrinolysis system. As the substrate specificity of these proteases for $\mathrm{C} 3$ is much lower than for their cognate substrates, the impact of such proteases under homeostatic conditions is probably minor. However, under pro-thrombotic conditions such as TMA, when control systems are exhausted and intravascular protease inhibitor concentration is low, such proteases are likely to cleave C3 and drive AP activation (Ekdahl et al., 2019). In light of these consideration, blocking of systemic AP activation by specific targeting of FD or MASP-3 seems difficult in patients suffering from ALI/ARDS with TMA or multiorgan failure.

As an alternative to FD, FB-targeting intervention has been developed by Ionis with Roche as a partner. They use a ligand-conjugated antisense drug to reduce the production of $\mathrm{FB}$, which is now in phase II trials for IgA nephropathy and age-related macular degeneration (AMD). At this point it is unclear, how efficient this drug would attenuate FB production in a severe systemic inflammatory disease state. We will only briefly touch molecules that destabilize the $\mathrm{C} 3$ convertase as clinical development of some of these molecules has either been discontinued (TP10 or TT30, extracellular variants of CR1)(Lazar et al., 2007; Risitano et al., 2012) or are still in pre-clinical development (mini-FH, Amyndas)(Schmidt et al., 2013).

As an alternative approach to target C3, conversion to C3 convertase has been selected by the Lambris lab. They selected a peptide from a phage library, compstatin, that prevents the binding of C3 to the assembled convertase independent of its origin (Sahu, Kay \& Lambris, 1996). Through several round of iteration, the affinity of this compound for C3 has been increased by more than 3 orders of magnitude as compared with the original compound resulting in CP40, which served as drug candidate for AMY-101 (Amyndas), which is now in phase II trials for periodontal disease and C3G (Mastellos, Ricklin \& Lambris, 2019). This approach of direct C3 targeting is attractive, as it is supposed to block virus-induced LP and CP activation as well as LP/CP-driven activation of the amplification loop at the bottleneck of all pathways (Figure 1). However, C3 is one of the most abundant plasms proteins with a concentration in the range of $1.5 \mathrm{mg} / \mathrm{ml}$. Thus, high amounts of inhibitor would be required to efficiently reduce circulating C3. The high turnover of C3 under strong inflammatory conditions would add to this problem. Finally, it remains to be determined whether compstatin derivatives would also prevent the cleavage of C3 by all circulating or cell derived serine proteases as outlined above. Despite these challenges, direct C3 targeting appears an attractive target in severe infection with highly pathogenic coronaviruses.

The list of compounds that specifically target the interaction of the small cleavage product of C3, the C3a anaphylatoxin with its C3aR is short. The selective nonpeptide C3aR antagonist SB 290157 has been generated almost 20 years ago(Ames et al., 2001). It has been used in with different success in several preclinical models to target C3aR. However, no clinical development has been pursued. During the past 10 years, the Fairlie lab has developed sophisticated approaches to design small molecule agonist and antagonists from proteins including C3a (Reid et al., 2013). In this context, they have recently reported on the new compound JR14a, a very potent C3aR antagonist that is 100-fold more potent than SB290157 (Rowley et al., 2020). This molecule awaits broad preclinical testing in animal models of inflammation.

\section{Targeting the terminal pathway}

\section{Targeting $C 5$}

The terminal complement complex (C5b-9, MAC) generation starts with the interaction of C5b, released from C5 convertase cleavage of C5, leading though several steps, to the generation C5b-9 and insertion of it into the cell plasma membrane as the membrane attack complex (MAC) that can cause endothelial cell damage. The complex promotes inflammation by inducing the expression of adhesion molecules and the release of chemokines and platelet activating factor, which can ultimately lead to dysregulation in the coagulation resulting in microvascular thrombosis. The ability of C5b-9 to upregulate expression of leucocyte adhesion molecules on the endothelial cell might also contribute to platelet localization and adhesion as well as increased leucocyte adhesion and subsequent cytokine and growth factor production (Dobrina et al., 2002).

Patients with TMA have increased production of the terminal complement components C5a, C5b and sub- 
sequently C5b-9, due to enhanced LP, CP or AP activation caused by defective regulation and/or excess activation (Figure 3). Elevated levels of circulating soluble C5b-9 (sC5b-9) can be measured in the blood of patients presenting with complement-mediated microangiopathies. High concentration of sub-lytic MAC in target cells may have a detrimental effect in variety of tissues like kidney, lung and the central nervous system. Selective inhibition of C5 convertases is one of the options to inhibit formation of C5b-9 (MAC) that has been successfully applied to clinical practice (Figure 1). Another method to inhibit C5 is to bind the ligand itself to prevent C5 convertases enzymatically cleaving C5 into C5a and C5b, the method that has been used in generating anti-C5 antibodies.

Eculizumab (Soliris, Alexion Pharmaceuticals) is a humanized murine monoclonal antibody against C5, which prevents C5 cleavage and limits both C5a and C5b production and prevents the generation of the terminal complement complex C5b-9 by any of the three complement pathways. Eculizumab was first approved for the treatment of paroxysmal nocturnal hemoglobinuria $(\mathrm{PNH})$, and the efficacy and safety of eculizumab for treating atypical hemolytic uremic syndrome (aHUS) were demonstrated in prospective clinical trials and was adopted for therapy in high risk TA-TMA patients (Legendre et al., 2013). Eculizumab (off-label) has been successfully used in HSCT recipients with severe TA-TMA and is one of the first complement blocking agent attempted in COVID-19 patients.

Complement mediated TA-TMA occurring in HSCT recipients very closely resembles histologic and clinical TMA presentation in subjects with COVID-19 suffering from a hyperinflammatory syndrome. Hyperinflammatory response in immunocompromised individuals with TA-TMA is often triggered by viral pathogens like BK virus(Laskin et al., 2019) influenza/parainfluenza (Bitzan \& Zieg, 2018), adenovirus(Yabe et al., 2005), HHV-6 (Belford, Myles, Magill, Wang, Myhand \& Waselenko, 2004) that is associated with very high systemic complement activation as measured by elevated blood sC5b-9 and leading to multi-organ injury resembling clinical and autopsy reports in SARS-CoV-2. Untreated patients with complement mediated TA-TMA have $>80 \%$ mortality due to multi-organ failure. Eculizumab treatment significantly improved survival as compared with untreated cohorts (66\% vs $17 \% 1$ y post-transplant survival) (Jodele et al., 2020a; Jodele et al., 2014). In HSCT recipients with TA-TMA pre-therapy, plasma sC5b-9 was associated with risk of dying from TMA. Plasma sC5b-9 also correlated with increased eculizumab drug clearance and was incorporated as one of the variables for use in pharmacokinetic/pharmacodynamic (PK/PD) eculizumab dosing algorithm for severely ill patients in order to achieve and to maintain therapeutic eculizumab levels (>100 $\mu \mathrm{g} / \mathrm{ml})$ for prompt control of TA-TMA (Jodele et al., 2016b).

Due to immediate need for clinical strategies how to manage vigorous complement activation an in SARSCoV-2 infected patients, we could adopt some of currently available knowledge in complement mediated TA-TMA in HSCT recipients. Eculizumab can be considered in COVID-19 population due to significant amount of knowledge using this drug in critically ill patients like HSCT recipients with TA-TMA, acceptable toxicity profile, and lack of interference with T-cell mediated anti-viral responses (Jodele et al., 2020a). Importantly, a first case study which applied eculizumab therapy COVID-19 patients suffering from ARDS or severe pneumonia resulted in successful recovery of all patients with reduction in inflammation (Diurno et al., 2020). Four subjects with confirmed severe, COVID-19-associated pneumonia with oxygen requirement and radiologic evidence of bilateral pneumonia were offered eculizumab. Despite patients presenting with a rapidly worsening respiratory function, all of them showed a marked clinical improvement within the first 48 hours after the first eculizumab dose with the median therapy time of 12.8 days to disease resolution. This first encouraging data warrant further evaluation in a larger cohort of COVID-19 patients.

Monitoring blood sC5b-9 can potentially serve as a helpful surrogate marker for enhanced C5 production in COVID-19 patients as the turnover of C5 will determine the clearance of eculizumab. In a high inflammatory state as can be seen in severely ill HSCT recipients with TA-TMA or COVID-19 patients, there is an acute phase response of the liver with massive $\mathrm{C} 5$ production and additional C5 production by activated circulating inflammatory cells and injured endothelial cells. Under such conditions, there are more target C5 molecules generated and more eculizumab is required as it forms immune complexes with the increased number of C5 molecules. Eculizumab serum concentration, sC5b-9 and CH50 monitoring tests are clinically available that 
can be adopted for PK/PD guided eculizumab dosing in COVID-19 patients as described in HSCT population (Jodele et al., 2016b). All patients receiving complement blockers should additionally receive antimicrobial prophylaxis appropriate for the prevention of meningococcal infection, as the available meningococcal vaccine does not provide adequate protection (Bouts, Monnens, Davin, Struijk \& Spanjaard, 2011; Struijk, Bouts, Rijkers, Kuin, ten Berge \& Bemelman, 2013). Complement blockade using eculizumab with appropriate antimicrobial prophylaxis was shown to be safe in immunocompromised HSCT recipients(Jodele et al., 2016a). Of note, last year Alexion launched a variant of eculizumab, i.e. ravulizumab, with longer plasma residence than eculizumab, allowing a less frequent dosing interval of 8 weeks(Kulasekararaj et al., 2019; Lee et al., 2019).

In addition to Eculizumab, several other C5-targeting antibodies have been developed, as genetic C5 variants have been resulting in poor binding and response to eculizumab inhibition (Nishimura et al., 2014). For example, Roche and Chugai developed SKY/RO7112689, which works in patients with the C5 variant p.Arg885His and long-lasting C5 inhibition properties (Fukuzawa et al., 2017). Also, Novartis (LFG316) and Regeneron (puzelimab/REGN3918) generated anti-C5 antibodies that are currently in clinical development.

A tick-derived C5 inhibitor nomacopan (Coversin, Akari therapeutics) is another complement inhibitory molecule that targets C5 and prevents the release of C5a and formation of C5b-9, although in a different way than eculizumab (Jore et al., 2016). In contrast to eculizumab, it is a recombinant small protein from the Ornithodros moubata tick. In addition to C5, it targets leukotriene/LTB4 that disrupts cell trafficking (in particular neutrophils) (Figure 2), cytokine release and provides a link between complement activation and coagulopathy with demonstrated effectiveness in a range of ARDS and sepsis pre-clinical models including those induced by viral infection like influenza H1N1(Garcia et al., 2013). It is likely that C5a and LTB4 together account for many of the pro-inflammatory effects associated with pulmonary inflammation and TMA (Figure 2) as observed COVID-19 patients with severe courses. Nomacopan is a small protein that is administered as continues subcutaneous infusion, which will potentially provide continuous complement blockade in the circulation. It demonstrated promising complement modulating response in TA-TMA and is now being examined in phase III clinical trials (Goodship et al., 2017).

Although terminal complement blockade provided significant improvement in TA-TMA, a more tailored approach targeting C5a or C5aR1 might be sufficient to cope with the deleterious, pro-inflammatory effects of overactivated complement.

\section{Blockade of the C5a/C5aR1 axis}

$\mathrm{C} 5 \mathrm{a}$ is generated in response to $\mathrm{C} 5$ cleavage by canonical and non-canonical complement activation. It exerts many of its pro-inflammatory properties through engagement of its cognate G-protein-coupled C5aR1. It also binds to C5aR2, which is uncoupled from G-proteins (Karasu, Nilsson, Kohl, Lambris \& Huber-Lang, 2019; Klos, Tenner, Johswich, Ager, Reis \& Kohl, 2009). At this point, most strategies to target C5a-mediated effects focus on C5aR1 (Figure 1). The most advanced approach uses a small molecule inhibitor of C5aR1, Avacopan (CCX168) developed by ChemoCentryx that is orally available. Avacopan has been demonstrated efficacy, safety and steroid sparing in a phase II trial for ANCA-associated vasculitis (Jayne et al., 2017) which was recently confirmed in a phase III trial and even showed superiority to standard glucocorticoid therapy. Innate Pharma has developed the fully human antibody advoralimab (IPH-5401), which is currently tested in patients with advanced solid tumors in a phase I trial together with the PD-L1 antibody durvalumab (AstraZeneca). Additional C5aR1 antagonists have been developed, which are still in the preclinical stage including, an allosteric inhibitor of C5aR1 (Dompe), or the cyclic peptide ALS-205 (Alsonex) based on PMX-53, a non-competitive inhibitor of C5aR1, which has been successfully used in several animal models of inflammatory diseases to target C5aR1 (Hawksworth, Li, Coulthard, Wolvetang \& Woodruff, 2017). Finally, the C5a mutein $\mathrm{A} 8^{\Delta 71-73}$ has been developed, primarily selected from a phage-display library, that simultaneously targets C5aR1 and C5aR2 (Heller et al., 1999). The antagonistic properties rely on an amino acid replacement at position 69 of C5a with a positively charged amino acid (Otto et al., 2004). This molecule has been shown in a preclinical model of sepsis to be superior to isolated C5aR1 targeting (Rittirsch et al., 2008). 
As alternative approach, InflaRx has developed the antibody IFX-1 that specifically targets hC5a (Figure 1). This antibody, which has been licensed to Staidson Biopharmaceutics (BDB-001) is currently used in a multicenter, randomized double blind placebo-controlled trial in mild COVID- 19 patients and an open label two-cohort clinical trial in patients with severe and critical COVID-19. First results were recently released showing a promising curative effect in two severe COVID-19 patients with moderate ARDS or pneumonia (Gao et al., 2020).

The available preclinical data and the few clinical data point toward a key role for C5a in complementdriven ARDS and TMA development in response to highly pathogenic coronavirus infection. The strong differences between C5a serum levels of COVID-19 patients with moderate and severe disease (Gao et al., 2020) indicate that longitudinal monitoring of C5a serum levels in patients with moderate disease might help to identify and stratify patients at risk to develop severe lung injury and TMA. Targeting C5a or C5aR1 might be superior to C5 targeting approaches as it is a more tailored approach that leaves the formation of the MAC intact, which is critical to combat infections with encapsulated bacteria including Neisseria meningitidis . Also, C3-fragment mediated opsonization is still possible. Also, the C5a/C5aR1 axis intersects and amplifies the responses of other innate immune receptors. For example, C5aR1 sets the threshold for IgG Fc receptor $(\mathrm{Fc} \gamma \mathrm{R})$-mediated immune cell activation as C5aR1 upregulates the expression

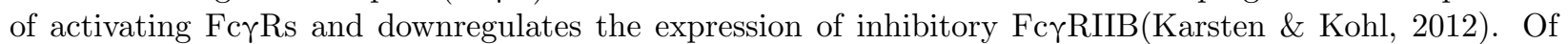
note, a significant association has been described between a SNP in FcrRIIA and the severity of SARS$\mathrm{CoV}$ infection (Yuan et al., 2005). Thus, C5aR targeting might also reduce virus-IgG-driven immune cell activation by activating Fc $\gamma$ Rs.

\section{Complement interaction with other inflammatory pathways and potential concurrent inter- ventions}

Complement system dysregulation is one of the major endothelial injury pathways. While complement blockade improves TMA, not all patients respond to therapy, prompting a search for additional targetable pathways of endothelial injury. Emerging data on COVID-19 affected population indicate that multiple inflammatory pathways are likely to interplay, and novel strategies personalized to each individual or combination therapies might be required to effectively fight the hyperinflammatory storm (Figure 2) (Barnes et al., 2020; Giamarellos-Bourboulis et al., 2020; Gloude et al., 2017; Zhao, 2020). In support of this view, proteomic and metabolomic profiling of sera from healthy controls, non-severe and severe COVID-19 patients identified changes in complement pathways in concert with platelet degranulation and macrophage function as the main variables to predict progression to severe COVID-19 disease(Shen et al., 2020). All of these pathways have formerly been associated with the development of TMA. Of note, the authors found strong increase in CRP in severely ill COVID-19 patients, which is strong non-canonical activator of complement by the CP (Biro et al., 2007). Recent data in HSCT recipients with TA-TMA suggests a key relationship between complement activation and increased interferon (IFN) signaling, NETs, and chemokines/cytokines like IL-8 and IL-6 forming an "IFN-complement loop" that can perpetuate endothelial injury and TMA. Recent RNAseq data in HSCT recipients with TMA showed that IFNs promote expression of complement genes, such as $\mathrm{C} 1 \mathrm{Q}$, which initiates the classical complement pathway and ultimately leads to formation of the lytic membrane attack complex (MAC or C5b-9) and endothelial injury presenting as TMA (Jodele et al., 2020b). Intracellular complement C5 production, cleavage into C5a and intracellular C5aR1 activation after $\mathrm{T}$ cell activation results in NLRP3 inflammasome activation, Th1 differentiation and production of IFN- $\gamma$ which could fuel the inflammatory scenario and sustain endothelial cell damage (Arbore et al., 2016).

Injured endothelial cells release IL-8, causing neutrophil activation and formation of NETs. In response, NET formation promotes complement system activation via the AP and FP (properdin) binding (Yuen et al., 2016). NET production can be further stimulated by IFN- $\gamma$ (Gloude et al., 2017). IFN- $\alpha$ and $-\beta$ increase differentiation of B cells into plasma cells that can produce anti-FH antibodies, preventing inhibition of the AP. NETs can activate plasmacytoid dendritic cells to produce high levels of IFN- $\alpha$ that can directly activate complement via C5b-9, resulting in vascular endothelial injury (Umemura et al., 2015).

Therapeutic administration of IFNs has been shown to cause TMA (Garcia-Romo et al., 2011). Viral 
pathogens that can trigger high IFN- $\gamma$ production may also lead to development of complement mediated TMA (Zareei et al., 2019). In addition, viruses can directly injure endothelial cells and promote release of IFN- $\gamma$ (An, Saenz Robles, Duray, Cantalupo \& Pipas, 2019). Inflammatory chemokines/cytokines like IL-6, IL-8, and IFN- $\gamma$ are also released from circulating activated T cells, NK cells, monocytes, and tissue macrophages as a response to viral infection, again contributing to TMA development.

Improved understanding in key cytokines roles in the "IFN-complement loop" provides us with new opportunities to combine therapies that might be used as personalized treatment options for selected patients. One clinical example is hemophagocytic lymphohistiocytosis (HLH), a rare clinical syndrome of excessive immune activation, characterized by signs and symptoms of extreme inflammation, driven mainly by IFN- $\gamma$ and other pro-inflammatory cytokines with good response to emapalumab (Lounder, Bin, de Min \& Jordan, 2019; Vallurupalli \& Berliner, 2019), a human monoclonal antibody to IFN- $\gamma$, which blocks its binding to cell surface receptors and activation of inflammatory signals. It is approved for treatment of severe HLH. Patients with HLH, who simultaneously present with complement-mediated TMA have high incidence of multi-organ injury and poor outcomes. Case series in children suggest that co-administration of both, an IFN- $\gamma$ blocker and a complement blocker targeting both pathways in TMA might provide faster disease control and recovery from organ injury (Gloude et al., 2020). Taking into consideration that COVID-19 affected subjects may preferentially have one of the other inflammatory pathways overactivated, monitoring blood sC5b-9 and CXCL9 (indicates activated IFN- $\gamma$ ) and IL-6 level will have immediate clinical implication in proposing care algorithms for patient risk stratification and targeted interventions, like implementation of complement, interferon, IL-6 modulating therapy using currently available drugs to halt COVID-19 progression to multi-organ failure and improve outcome.

\section{Conclusion and future perspective}

In summary, the available data strongly support a model in which complement activation in the lung and in other organs is a critical host mediator of SARS-CoV-2-induced development of atypical ARDS and TMA. We would like to propose a model in which strong complement activation by the LP and/or the CP occurs in patients suffering from atypical ARDS/TMA resulting in massive generation of C5a. Polymorphisms in exon 1 and/or the promoter region of MBL or in complement regulators may define the extent of complement activation, in particular in African Americans. Alternatively, and not mutually exclusive, the extent of virus-specific neutralizing IgG Abs generated after the first week of infection may determine the magnitude of complement activation. Importantly, C5a controls the threshold of IgG Fc receptor expression as an important mechanism of IgG-mediated innate immune cell activation (Karsten \& Kohl, 2012). Complement activation occurs primarily in the lower airways but will result in the release of C5a into the circulation. Such C5a recruits and activates proinflammatory immune cells as a key mechanism that drives the "cytokine and chemokine storm" associated with fatal lung injury and TMA development (Figure 2). Thus, targeting C5, C5a or its primary receptor, C5aR1, should be considered to alleviate the proinflammatory effects, reduce lung pathology and increase the survival of COVID-19 patients.

\section{Source of Funding}

The work of J.K. is supported by the German Research Foundation IRTG 1911 and EXC2167. The work of S. J. is funded by the Eunice Kennedy Shriver National Institute of Child Health and Human Development of the National Institute of Health (NIH) under award number R01HD093773. The content is solely the responsibility of the author and does not necessarily represent the official views of the National Institutes of Health.

Conflict of interest statement: J.K. has no conflict of interest to declare. S. J. submitted a US patent application entitled: Compositions and methods for treating TA-TMA. Further, she conducted an NIHfunded study with the study drug provided by Alexion pharmaceuticals at no charge to study subjects. Finally, she received travel support from Omeros corporation. 


\section{References}

Adriani KS, Brouwer MC, Geldhoff M, Baas F, Zwinderman AH, Paul Morgan B, et al. (2013). Common polymorphisms in the complement system and susceptiblity to bacterial meningitis. J Infect 66:255-262.

Ames RS, Lee D, Foley JJ, Jurewicz AJ, Tornetta MA, Bautsch W, et al. (2001). Identification of a selective nonpeptide antagonist of the anaphylatoxin $\mathrm{C} 3 \mathrm{a}$ receptor that demonstrates antiinflammatory activity in animal models. J Immunol 166: 6341-6348.

An P, Saenz Robles MT, Duray AM, Cantalupo PG, \& Pipas JM (2019). Human polyomavirus BKV infection of endothelial cells results in interferon pathway induction and persistence. PLoS Pathog 15: e1007505.

Antoniou K, Ender F, Vollbrandt T, Laumonnier Y, Rathmann F, Pasare C, et al. (2020). AllergenInduced C5a/C5aR1 Axis Activation in Pulmonary CD11b(+) cDCs Promotes Pulmonary Tolerance through Downregulation of CD40. Cells 9.

Arbore G, West EE, Spolski R, Robertson AAB, Klos A, Rheinheimer C, et al. (2016). T helper 1 immunity requires complement-driven NLRP3 inflammasome activity in CD4(+) T cells. Science 352:aad1210.

Asgari E, Le Friec G, Yamamoto H, Perucha E, Sacks SS, Kohl J, et al. (2013). C3a modulates IL-1beta secretion in human monocytes by regulating ATP efflux and subsequent NLRP3 inflammasome activation. Blood 122: 3473-3481.

Baker KS, Davies SM, Majhail NS, Hassebroek A, Klein JP, Ballen KK, et al. (2009). Race and socioeconomic status influence outcomes of unrelated donor hematopoietic cell transplantation. Biol Blood Marrow Transplant 15: 1543-1554.

Barnes BJ, Adrover JM, Baxter-Stoltzfus A, Borczuk A, Cools-Lartigue J, Crawford JM, et al. (2020). Targeting potential drivers of COVID-19: Neutrophil extracellular traps. J Exp Med 217.

Belford A, Myles O, Magill A, Wang J, Myhand RC, \& Waselenko JK (2004). Thrombotic microangiopathy (TMA) and stroke due to human herpesvirus-6 (HHV-6) reactivation in an adult receiving high-dose melphalan with autologous peripheral stem cell transplantation. Am J Hematol 76: 156-162.

Bernig T, Taylor JG, Foster CB, Staats B, Yeager M, \& Chanock SJ (2004). Sequence analysis of the mannose-binding lectin (MBL2) gene reveals a high degree of heterozygosity with evidence of selection. Genes Immun 5: 461-476.

Biro A, Rovo Z, Papp D, Cervenak L, Varga L, Fust G, et al.(2007). Studies on the interactions between C-reactive protein and complement proteins. Immunology 121: 40-50.

Bitzan M, \& Zieg J (2018). Influenza-associated thrombotic microangiopathies. Pediatr Nephrol 33: 20092025.

Borosss P, Yildiz C, Simons PJ, Boon L, \& Hack CE (2016). A monoclonal antibody against complement C2 as a novel inhibitor. In Atlant Conference 2016:Innate Host Defence. Utrecht, The Netherlands.

Bouts A, Monnens L, Davin JC, Struijk G, \& Spanjaard L (2011). Insufficient protection by Neisseria meningitidis vaccination alone during eculizumab therapy. Pediatr Nephrol 26: 1919-1920.

Che XY, Qiu LW, Pan YX, Wen K, Hao W, Zhang LY, et al. (2004). Sensitive and specific monoclonal antibody-based capture enzyme immunoassay for detection of nucleocapsid antigen in sera from patients with severe acute respiratory syndrome. J Clin Microbiol 42:2629-2635.

Chen L, Li X, Chen M, Feng Y, \& Xiong C (2020). The ACE2 expression in human heart indicates new potential mechanism of heart injury among patients infected with SARS-CoV-2. Cardiovasc Res.

Chen S, Lu D, Zhang M, Che J, Yin Z, Zhang S, et al. (2005). Double-antigen sandwich ELISA for detection of antibodies to SARS-associated coronavirus in human serum. Eur J Clin Microbiol Infect Dis 24: 549-553. 
Davila S, Wright VJ, Khor CC, Sim KS, Binder A, Breunis WB, et al. (2010). Genome-wide association study identifies variants in the $\mathrm{CFH}$ region associated with host susceptibility to meningococcal disease. Nat Genet 42: 772-776.

Diurno F, Numis FG, Porta G, Cirillo F, Maddaluno S, Ragozzino A, et al. (2020). Eculizumab treatment in patients with COVID-19: preliminary results from real life ASL Napoli 2 Nord experience. Eur Rev Med Pharmacol Sci 24: 4040-4047.

Dobo J, Szakacs D, Oroszlan G, Kortvely E, Kiss B, Boros E, et al. (2016). MASP-3 is the exclusive profactor D activator in resting blood: the lectin and the alternative complement pathways are fundamentally linked. Sci Rep 6: 31877.

Dobrina A, Pausa M, Fischetti F, Bulla R, Vecile E, Ferrero E, et al. (2002). Cytolytically inactive terminal complement complex causes transendothelial migration of polymorphonuclear leukocytes in vitro and in vivo. Blood 99: 185-192.

Ekdahl KN, Mohlin C, Adler A, Aman A, Manivel VA, Sandholm K, et al. (2019). Is generation of C3(H2O) necessary for activation of the alternative pathway in real life? Mol Immunol 114: 353-361.

Ekdahl KN, Teramura Y, Hamad OA, Asif S, Duehrkop C, Fromell K, et al. (2016). Dangerous liaisons: complement, coagulation, and kallikrein/kinin cross-talk act as a linchpin in the events leading to thromboinflammation. Immunol Rev 274: 245-269.

el-Lati SG, Dahinden CA, \& Church MK (1994). Complement peptides C3a- and C5a-induced mediator release from dissociated human skin mast cells. J Invest Dermatol 102: 803-806.

Fischer WH, \& Hugli TE (1997). Regulation of B cell functions by C3a and C3a(desArg): suppression of TNF-alpha, IL-6, and the polyclonal immune response. J Immunol 159: 4279-4286.

Fischer WH, Jagels MA, \& Hugli TE (1999). Regulation of IL-6 synthesis in human peripheral blood mononuclear cells by C3a and C3a(desArg). J Immunol 162: 453-459.

Fox SE, Akmatbekov A, Harbert JL, Li G, Brown Q, \& Vander Heide RS (2020). Pulmonary and cardiac pathology in COVID-19: the first autopsy series from New Orleans: medRxiv.

Fukuoka Y, \& Hugli TE (1988). Demonstration of a specific C3a receptor on guinea pig platelets. J Immunol 140: 3496-3501.

Fukuzawa T, Sampei Z, Haraya K, Ruike Y, Shida-Kawazoe M, Shimizu Y, et al. (2017). Long lasting neutralization of C5 by SKY59, a novel recycling antibody, is a potential therapy for complement-mediated diseases. Sci Rep 7: 1080.

Gao T, Hu M, Zhang X, Li H, Zhu L, Liu H, et al. (2020). Highly pathogenic coronavirus $\mathrm{N}$ protein aggravates lung injury by MASP-2.mediated complement over-activation. doi: doi: https://doi.org/10.1101/2020.03.29.20041962

Garcia CC, Weston-Davies W, Russo RC, Tavares LP, Rachid MA, Alves-Filho JC, et al. (2013). Complement C5 activation during influenza A infection in mice contributes to neutrophil recruitment and lung injury. PLoS One 8: e64443.

Garcia-Romo GS, Caielli S, Vega B, Connolly J, Allantaz F, Xu Z, et al. (2011). Netting neutrophils are major inducers of type I IFN production in pediatric systemic lupus erythematosus. Sci Transl Med 3: $73 \mathrm{ra} 20$.

Garred P, Genster N, Pilely K, Bayarri-Olmos R, Rosbjerg A, Ma YJ, et al. (2016). A journey through the lectin pathway of complement-MBL and beyond. Immunol Rev 274: 74-97.

Garred P, J JS, Quist L, Taaning E, \& Madsen HO (2003). Association of mannose-binding lectin polymorphisms with sepsis and fatal outcome, in patients with systemic inflammatory response syndrome. J Infect 
Dis 188: 1394-1403.

Garred P, Larsen F, Seyfarth J, Fujita R, \& Madsen HO (2006). Mannose-binding lectin and its genetic variants. Genes Immun 7:85-94.

Gattinoni L, Coppola S, Cressoni M, Busana M, Rossi S, \& Chiumello D (2020). Covid-19 Does Not Lead to a "Typical" Acute Respiratory Distress Syndrome. Am J Respir Crit Care Med.

Giamarellos-Bourboulis EJ, Netea MG, Rovina N, Akinosoglou K, Antoniadou A, Antonakos N, et al. (2020). Complex Immune Dysregulation in COVID-19 Patients with Severe Respiratory Failure. Cell Host Microbe.

Gloude NJ, Dandoy CE, Davies SM, Myers KC, Jordan MB, Marsh R, et al. (2020). Thinking beyond HLH: clinical features of patients with concurrent presentation of hemophagocytic lymphohistiocytosis and thrombotic microangiopathy. Biol Blood Marrow Transplant 26:S15-S16.

Gloude NJ, Khandelwal P, Luebbering N, Lounder DT, Jodele S, Alder MN, et al. (2017). Circulating dsDNA, endothelial injury, and complement activation in thrombotic microangiopathy and GVHD. Blood 130: $1259-1266$.

Gong MN, Zhou W, Williams PL, Thompson BT, Pothier L, \& Christiani DC (2007). Polymorphisms in the mannose binding lectin-2 gene and acute respiratory distress syndrome. Crit Care Med 35: 48-56.

Goodship THJ, Pinto F, Weston-Davies WH, Silva J, Nishimura JI, Nunn MA, et al. (2017). Use of the complement inhibitor Coversin to treat HSCT-associated TMA. Blood Adv 1: 1254-1258.

Gralinski LE, Sheahan TP, Morrison TE, Menachery VD, Jensen K, Leist SR, et al. (2018). Complement Activation Contributes to Severe Acute Respiratory Syndrome Coronavirus Pathogenesis. mBio 9.

Guan M, Chen HY, Foo SY, Tan YJ, Goh PY, \& Wee SH (2004). Recombinant protein-based enzyme-linked immunosorbent assay and immunochromatographic tests for detection of immunoglobulin G antibodies to severe acute respiratory syndrome (SARS) coronavirus in SARS patients. Clin Diagn Lab Immunol 11: $287-291$.

Guglietta S, Chiavelli A, Zagato E, Krieg C, Gandini S, Ravenda PS, et al. (2016). Coagulation induced by C3aR-dependent NETosis drives protumorigenic neutrophils during small intestinal tumorigenesis. Nat Commun 7: 11037.

Hawksworth OA, Li XX, Coulthard LG, Wolvetang EJ, \& Woodruff TM (2017). New concepts on the therapeutic control of complement anaphylatoxin receptors. Mol Immunol 89: 36-43.

Hayashi M, Machida T, Ishida Y, Ogata Y, Omori T, Takasumi M, et al. (2019). Cutting Edge: Role of MASP-3 in the Physiological Activation of Factor D of the Alternative Complement Pathway. J Immunol 203: $1411-1416$.

Hellemann D, Larsson A, Madsen HO, Bonde J, Jarlov JO, Wiis J, et al. (2007). Heterozygosity of mannosebinding lectin (MBL2) genotypes predicts advantage (heterosis) in relation to fatal outcome in intensive care patients. Hum Mol Genet 16: 3071-3080.

Heller T, Hennecke M, Baumann U, Gessner JE, zu Vilsendorf AM, Baensch M, et al. (1999). Selection of a C5a receptor antagonist from phage libraries attenuating the inflammatory response in immune complex disease and ischemia/reperfusion injury. J Immunol 163:985-994.

Heurich M, Martinez-Barricarte R, Francis NJ, Roberts DL, Rodriguez de Cordoba S, Morgan BP, et al. (2011). Common polymorphisms in C3, factor B, and factor H collaborate to determine systemic complement activity and disease risk. Proc Natl Acad Sci U S A 108:8761-8766.

Hoffmann M, Kleine-Weber H, Schroeder S, Kruger N, Herrler T, Erichsen S, et al. (2020). SARS-CoV-2 Cell Entry Depends on ACE2 and TMPRSS2 and Is Blocked by a Clinically Proven Protease Inhibitor. Cell. 
Ip WK, Chan KH, Law HK, Tso GH, Kong EK, Wong WH, et al. (2005). Mannose-binding lectin in severe acute respiratory syndrome coronavirus infection. J Infect Dis 191: 1697-1704.

Jager U, D’Sa S, Schorgenhofer C, Bartko J, Derhaschnig U, Sillaber C, et al. (2019). Inhibition of complement $\mathrm{C} 1 \mathrm{~s}$ improves severe hemolytic anemia in cold agglutinin disease: a first-in-human trial. Blood 133: 893-901.

Jayne DRW, Bruchfeld AN, Harper L, Schaier M, Venning MC, Hamilton P, et al. (2017). Randomized Trial of C5a Receptor Inhibitor Avacopan in ANCA-Associated Vasculitis. J Am Soc Nephrol 28:2756-2767.

Jiang Y, Li J, Teng Y, Sun H, Tian G, He L, et al. (2019). Complement Receptor C5aR1 Inhibition Reduces Pyroptosis in hDPP4-Transgenic Mice Infected with MERS-CoV. Viruses 11.

Jiang Y, Zhao G, Song N, Li P, Chen Y, Guo Y, et al. (2018). Blockade of the C5a-C5aR axis alleviates lung damage in hDPP4-transgenic mice infected with MERS-CoV. Emerg Microbes Infect 7: 77.

Jodele S, Dandoy CE, Danziger-Isakov L, Myers KC, El-Bietar J, Nelson A, et al. (2016a). Terminal Complement Blockade after Hematopoietic Stem Cell Transplantation Is Safe without Meningococcal Vaccination. Biol Blood Marrow Transplant 22: 1337-1340.

Jodele S, Dandoy CE, Lane A, Laskin BL, Teusink-Cross A, Myers KC, et al. (2020a). Complement blockade for TA-TMA: lessons learned from a large pediatric cohort treated with eculizumab. Blood 135:1049-1057.

Jodele S, Davies SM, Lane A, Khoury J, Dandoy C, Goebel J, et al.(2014). Diagnostic and risk criteria for HSCT-associated thrombotic microangiopathy: a study in children and young adults. Blood 124: 645-653.

Jodele S, Fukuda T, Mizuno K, Vinks AA, Laskin BL, Goebel J, et al. (2016b). Variable Eculizumab Clearance Requires Pharmacodynamic Monitoring to Optimize Therapy for Thrombotic Microangiopathy after Hematopoietic Stem Cell Transplantation. Biol Blood Marrow Transplant 22: 307-315.

Jodele S, Medvedovic M, Luebbering N, Chen J, Dandoy CE, Laskin BL, et al. (2020b). Interferoncomplement loop in transplant-associated thrombotic microangiopathy. Blood Adv 4:1166-1177.

Jodele S, Zhang K, Dandoy CE, Myers KC, Lane A, \& Davies SM (2017). Donor genotype and susceptibility to transplant-associated thrombotic microangiopathy. Biol Blood Marrow Transplant 03.

Jodele S, Zhang K, Zou F, Laskin B, Dandoy CE, Myers KC, et al.(2016c). The genetic fingerprint of susceptibility for transplant-associated thrombotic microangiopathy. Blood 127:989-996.

Jore MM, Johnson S, Sheppard D, Barber NM, Li YI, Nunn MA, et al.(2016). Structural basis for therapeutic inhibition of complement C5. Nat Struct Mol Biol 23: 378-386.

Karasu E, Nilsson B, Kohl J, Lambris JD, \& Huber-Lang M (2019). Targeting Complement Pathways in Polytrauma- and Sepsis-Induced Multiple-Organ Dysfunction. Front Immunol 10: 543.

Karsten CM, \& Kohl J (2012). The immunoglobulin, IgG Fc receptor and complement triangle in autoimmune diseases. Immunobiology 217:1067-1079.

Klos A, Tenner AJ, Johswich KO, Ager RR, Reis ES, \& Kohl J (2009). The role of the anaphylatoxins in health and disease. Mol Immunol 46: 2753-2766.

Kordowski A, Reinicke AT, Wu D, Orinska Z, Hagemann P, Huber-Lang M, et al. (2019). C5a receptor 1(-/-) mice are protected from the development of IgE-mediated experimental food allergy. Allergy 74: 767-779.

Kretzschmar T, Jeromin A, Gietz C, Bautsch W, Klos A, Kohl J, et al. (1993). Chronic myelogenous leukemia-derived basophilic granulocytes express a functional active receptor for the anaphylatoxin C3a. Eur J Immunol 23: 558-561. 
Kulasekararaj AG, Hill A, Rottinghaus ST, Langemeijer S, Wells R, Gonzalez-Fernandez FA, et al. (2019). Ravulizumab (ALXN1210) vs eculizumab in C5-inhibitor-experienced adult patients with PNH: the 302 study. Blood 133: 540-549.

Laskin BL, Denburg MR, Furth SL, Moatz T, Altrich M, Kleiboeker S, et al. (2019). The natural history of BK polyomavirus and the host immune response after stem cell transplantation. Clin Infect Dis.

Laumonnier Y, Karsten CM, \& Kohl J (2017). Novel insights into the expression pattern of anaphylatoxin receptors in mice and men. Mol Immunol 89: 44-58.

Lazar HL, Keilani T, Fitzgerald CA, Shapira OM, Hunter CT, Shemin RJ, et al. (2007). Beneficial effects of complement inhibition with soluble complement receptor 1 (TP10) during cardiac surgery: is there a gender difference? Circulation 116: I83-88.

Lee JW, Sicre de Fontbrune F, Wong Lee Lee L, Pessoa V, Gualandro S, Fureder W, et al. (2019). Ravulizumab (ALXN1210) vs eculizumab in adult patients with PNH naive to complement inhibitors: the 301 study. Blood 133: 530-539.

Legendre CM, Licht C, Muus P, Greenbaum LA, Babu S, Bedrosian C, et al. (2013). Terminal complement inhibitor eculizumab in atypical hemolytic-uremic syndrome. N Engl J Med 368: 2169-2181.

Levi M, Cohn DM, \& Zeerleder S (2019). Hereditary angioedema: Linking complement regulation to the coagulation system. Res Pract Thromb Haemost 3: 38-43.

Lipworth B, Chan R, Lipworth S, \& RuiWen Kuo C (2020). Weathering the cytokine storm in susceptible patients with severe SARS-CoV-2 infection. J Allergy Clin Immunol Pract.

Liu W, Liu L, Kou G, Zheng Y, Ding Y, Ni W, et al. (2020). Evaluation of Nucleocapsid and Spike Protein-based ELISAs for detecting antibodies against SARS-CoV-2. J Clin Microbiol.

Lounder DT, Bin Q, de Min C, \& Jordan MB (2019). Treatment of refractory hemophagocytic lymphohistiocytosis with emapalumab despite severe concurrent infections. Blood Adv 3: 47-50.

Madsen HO, Garred P, Thiel S, Kurtzhals JA, Lamm LU, Ryder LP, et al. (1995). Interplay between promoter and structural gene variants control basal serum level of mannan-binding protein. J Immunol 155: 3013-3020.

Magro C, Mulvey JJ, Berlin D, Nuovo G, Salvatore S, Harp J, et al. (2020). Complement associated microvascular injury and thrombosis in the pathogenesis of severe COVID-19 infection: A report of five cases. Transl Res.

Mastellos DC, Ricklin D, \& Lambris JD (2019). Clinical promise of next-generation complement therapeutics. Nat Rev Drug Discov 18: 707-729.

[Online] Available from https://clinicaltrials.gov/ct2/results?cond=Thrombotic+Microangiopathies\&term=OMS721\&cntry= [Accessed: 042020 2020].

[Online] Available from https://www.clinicaltrials.gov/ct2/show/NCT03347396?term=NCT03347396\&rank=1. [Accessed].

Meliopoulos VA, Karlsson EA, Kercher L, Cline T, Freiden P, Duan S, et al. (2014). Human H7N9 and H5N1 influenza viruses differ in induction of cytokines and tissue tropism. J Virol 88:12982-12991.

Nishimura J, Yamamoto M, Hayashi S, Ohyashiki K, Ando K, Brodsky AL, et al. (2014). Genetic variants in C5 and poor response to eculizumab. N Engl J Med 370: 632-639.

Ohta R, Torii Y, Imai M, Kimura H, Okada N, \& Ito Y (2011). Serum concentrations of complement anaphylatoxins and proinflammatory mediators in patients with 2009 H1N1 influenza. Microbiol Immunol 55: 191-198. 
Otto M, Hawlisch H, Monk PN, Muller M, Klos A, Karp CL, et al.(2004). C5a mutants are potent antagonists of the C5a receptor (CD88) and of C5L2: position 69 is the locus that determines agonism or antagonism. J Biol Chem 279: 142-151.

Ou X, Liu Y, Lei X, Li P, Mi D, Ren L, et al. (2020). Characterization of spike glycoprotein of SARS-CoV-2 on virus entry and its immune cross-reactivity with SARS-CoV. Nat Commun 11: 1620.

Paun CC, Lechanteur YTE, Groenewoud JMM, Altay L, Schick T, Daha MR, et al. (2016). A Novel Complotype Combination Associates with Age-Related Macular Degeneration and High Complement Activation Levels in vivo. Sci Rep 6: 26568.

Peiris JS, Chu CM, Cheng VC, Chan KS, Hung IF, Poon LL, et al.(2003). Clinical progression and viral load in a community outbreak of coronavirus-associated SARS pneumonia: a prospective study. Lancet 361: $1767-1772$.

Reid RC, Yau MK, Singh R, Hamidon JK, Reed AN, Chu P, et al.(2013). Downsizing a human inflammatory protein to a small molecule with equal potency and functionality. Nat Commun 4: 2802.

Ricklin D, Mastellos DC, Reis ES, \& Lambris JD (2018). The renaissance of complement therapeutics. Nat Rev Nephrol 14: 26-47.

Ricklin D, Reis ES, Mastellos DC, Gros P, \& Lambris JD (2016). Complement component C3 - The "Swiss Army Knife" of innate immunity and host defense. Immunol Rev 274: 33-58.

Risitano AM, Notaro R, Pascariello C, Sica M, del Vecchio L, Horvath CJ, et al. (2012). The complement receptor 2 /factor $\mathrm{H}$ fusion protein TT30 protects paroxysmal nocturnal hemoglobinuria erythrocytes from complement-mediated hemolysis and C3 fragment. Blood 119:6307-6316.

Rittirsch D, Flierl MA, Nadeau BA, Day DE, Huber-Lang M, Mackay CR, et al. (2008). Functional roles for C5a receptors in sepsis. Nat Med 14: 551-557.

Rowley JA, Reid RC, Poon EKY, Wu KC, Lim J, Lohman RJ, et al.(2020). Potent Thiophene Antagonists of Human Complement C3a Receptor with Anti-Inflammatory Activity. J Med Chem 63: 529-541.

Sahu A, Kay BK, \& Lambris JD (1996). Inhibition of human complement by a C3-binding peptide isolated from a phage-displayed random peptide library. J Immunol 157: 884-891.

Schindler R, Gelfand JA, \& Dinarello CA (1990). Recombinant C5a stimulates transcription rather than translation of interleukin-1 (IL-1) and tumor necrosis factor: translational signal provided by lipopolysaccharide or IL-1 itself. Blood 76: 1631-1638.

Schmidt CQ, Bai H, Lin Z, Risitano AM, Barlow PN, Ricklin D, et al. (2013). Rational engineering of a minimized immune inhibitor with unique triple-targeting properties. J Immunol 190: 5712-5721.

Shen B, Yi X, Sun Y, Bi X, Du J, Zhang C, et al. (2020). Proteomic and Metabolomic characterization of COVID-19 patient sera. doi: doi: https://doi.org/10.1101/2020.04.07.20054585

Shi J, Rose EL, Singh A, Hussain S, Stagliano NE, Parry GC, et al. (2014). TNT003, an inhibitor of the serine protease C1s, prevents complement activation induced by cold agglutinins. Blood 123:4015-4022.

Steffensen R, Thiel S, Varming K, Jersild C, \& Jensenius JC (2000). Detection of structural gene mutations and promoter polymorphisms in the mannan-binding lectin (MBL) gene by polymerase chain reaction with sequence-specific primers. J Immunol Methods 241: 33-42.

Struijk GH, Bouts AH, Rijkers GT, Kuin EA, ten Berge IJ, \& Bemelman FJ (2013). Meningococcal sepsis complicating eculizumab treatment despite prior vaccination. Am J Transplant 13: 819-820.

Sun S, Zhao G, Liu C, Fan W, Zhou X, Zeng L, et al. (2015). Treatment with anti-C5a antibody improves the outcome of H7N9 virus infection in African green monkeys. Clin Infect Dis 60:586-595. 
Sun S, Zhao G, Liu C, Wu X, Guo Y, Yu H, et al. (2013). Inhibition of complement activation alleviates acute lung injury induced by highly pathogenic avian influenza H5N1 virus infection. Am J Respir Cell Mol Biol 49: 221-230.

Thye T, Niemann S, Walter K, Homolka S, Intemann CD, Chinbuah MA, et al. (2011). Variant G57E of mannose binding lectin associated with protection against tuberculosis caused by Mycobacterium africanum but not by M. tuberculosis. PLoS One 6: e20908.

Tu X, Chong WP, Zhai Y, Zhang H, Zhang F, Wang S, et al. (2015). Functional polymorphisms of the CCL2 and MBL genes cumulatively increase susceptibility to severe acute respiratory syndrome coronavirus infection. J Infect 71: 101-109.

Umemura M, Miwa Y, Yanai R, Isojima S, Tokunaga T, Tsukamoto H, et al. (2015). A case of Degos disease: demonstration of C5b-9-mediated vascular injury. Mod Rheumatol 25: 480-483.

[Online] Available from https://gisanddata.maps.arcgis.com/apps/opsdashboard/index.html\#/bda7594740fd40299423467b48 [Accessed].

Vallurupalli M, \& Berliner N (2019). Emapalumab for the treatment of relapsed/refractory hemophagocytic lymphohistiocytosis. Blood 134: 1783-1786.

Wang R, Xiao H, Guo R, Li Y, \& Shen B (2015). The role of C5a in acute lung injury induced by highly pathogenic viral infections. Emerg Microbes Infect 4: e28.

Weaver DJ, Jr., Reis ES, Pandey MK, Kohl G, Harris N, Gerard C, et al. (2010). C5a receptor-deficient dendritic cells promote induction of Treg and Th17 cells. Eur J Immunol 40: 710-721.

Wolfel R, Corman VM, Guggemos W, Seilmaier M, Zange S, Muller MA, et al. (2020). Virological assessment of hospitalized patients with COVID-2019. Nature.

Xu Z, Shi L, Wang Y, Zhang J, Huang L, Zhang C, et al. (2020). Pathological findings of COVID-19 associated with acute respiratory distress syndrome. Lancet Respir Med 8: 420-422.

Yabe H, Hattori K, Inoue H, Matsumoto M, Hamanoue S, Hiroi A, et al. (2005). Fatal adenovirus infection indistinguishable from thrombotic microangiopathy after allogeneic CD34+ peripheral progenitor cell transplantation. Tokai J Exp Clin Med 30: 71-75.

Yuan FF, Tanner J, Chan PK, Biffin S, Dyer WB, Geczy AF, et al.(2005). Influence of FcgammaRIIA and MBL polymorphisms on severe acute respiratory syndrome. Tissue Antigens 66: 291-296.

Yuen J, Pluthero FG, Douda DN, Riedl M, Cherry A, Ulanova M, et al. (2016). NETosing Neutrophils Activate Complement Both on Their Own NETs and Bacteria via Alternative and Non-alternative Pathways. Front Immunol 7: 137.

Zareei N, Miri HR, Karimi MH, Afshari A, Geramizadeh B, Roozbeh J, et al. (2019). Increasing of the interferon-gamma gene expression during polyomavirus BK infection in kidney transplant patients. Microb Pathog 129: 187-194.

Zhang H, Zhou G, Zhi L, Yang H, Zhai Y, Dong X, et al. (2005). Association between mannose-binding lectin gene polymorphisms and susceptibility to severe acute respiratory syndrome coronavirus infection. J Infect Dis 192: 1355-1361.

Zhao M (2020). Cytokine storm and immunomodulatory therapy in COVID-19: role of chloroquine and anti-IL-6 monoclonal antibodies. Int J Antimicrob Agents: 105982.

Zhou Y, Lu K, Pfefferle S, Bertram S, Glowacka I, Drosten C, et al. (2010). A single asparagine-linked glycosylation site of the severe acute respiratory syndrome coronavirus spike glycoprotein facilitates inhibition by mannose-binding lectin through multiple mechanisms. J Virol 84: 8753-8764.

Figure legends 
Figure 1. SARS-CoV-2 driven complement activation and potential targets of the complement cascade. Several structural proteins of SARS-CoV-2 including the S and N proteins are recognized by MBL resulting in virus-induced activation of the LP. Sensing of the virus by the innate immune system results in the activation of $\mathrm{B}$ and $\mathrm{T}$ cells of the adaptive immune system, eventually leading to the production of virusspecific IgM and IgG antibodies. Such antibodies activate the complement system by the CP in addition to the LP. LP and CP activation initiate a cascade or proteolytic events that forms the C4bC2 convertase, eventually cleaving C3 into C3a and C3b. This C3b serves as the nucleus of the amplification (A) loop that results in the ongoing cleavage of $\mathrm{C} 3$, unless controlled by complement regulator proteins. The emerging $\mathrm{C} 3$ convertase of the $\mathrm{AP}, \mathrm{C} 3 \mathrm{bBb}$ can form the $\mathrm{C} 5$ convertase $\mathrm{C} 3 \mathrm{bBb} 3 \mathrm{~b}$ of the AP that consecutively cleaves C5a into C5a and C5b, the latter of which can assemble together with C6-C9 to build the MAC. Several compounds have been generated that specifically target the activation of the LP at the level of the serine protease MASP-2 or the CP at the level of C1q and C1s. Further, compounds have been developed to inhibit the cleavage of $\mathrm{C} 3$ by either targeting molecules that build the AP C3 convertase of by protecting C3 from C3 convertase-mediated cleavage. Downstream of C3, antibodies and inhibitors of C5 have been generated that protect $\mathrm{C} 5$ from cleavage by $\mathrm{C} 5$ convertases. Finally, distinct approaches resulted in antibodies that target C5a or antagonists of its primary receptor, C5aR1. The potential use of such complement inhibitors in COVID-19 infection is discussed in the text.

Figure 2. Complement effector functions leading to SARS-CoV-2-induced thrombotic microangiopathy (TMA) and acute lung injury. SARS-CoV-2-sensing by pattern recognition molecules of the LP and CP results in C5 cleavage and the generation of the C5a anaphylatoxin. Further, LP-derived MAPSs activate the coagulation and the kinin system to ignite TMA leading to fibrin formation and platelet aggregation. C5a attracts neutrophils and inflammatory monocytes to adhere at the vascular endothelium, release IL-8 and multiple inflammatory cytokines and form NETs. Such NETs can activate complement by the AP and fuel the C3 amplification loop (A), when complement regulators are exhausted and/or exhibit reduced function due to loss of function mutations. Also, adherent neutrophils produce LTB4 that binds to it cognate receptor driving neutrophil transmigration into the lung. C5a-activated monocytes in concert with activated neutrophils produce proinflammatory cytokines and chemokines that further activate the endothelium and amplify inflammation. Virus-induced complement activation by the LP within the lung tissue is an additional source of C5a. It activates neutrophils and inflammatory monocytes that were recruited to the lung, as well as tissue-resident macrophages to produce pro-inflammatory chemokines and cytokines, eventually driving tissue damage leading to ALI and ARDS development.

Figure 3. Impact of inherited gain- or loss-of function mutations in complement activator or regulator proteins on complement pathway activation. The degree of complement activation in response to infection is defined by the strength of the activation by complement activator molecules, the formation of the critical AP amplification loop and the potency of the system to balance this activation by complement regulator molecules. (A) Balanced complement activation occurs, when sensing of the SARS-CoV-2 virus by MBL or virus-specific antibodies is appropriately controlled by complement regulator proteins resulting in innate immunity-guided activation of adaptive immune responses eventually leading to virus elimination. (B) Polymorphisms in a set of complement proteins, either associated with a gain-of function in complement activators or loss-of function in complement regulators, or both, can aggregate to effects leading to complement overactivation as has been observed in African Americans with HSCT-TMA. In case of SARS-CoV-2 infection, such aggregation of inherited variants of complement proteins may lead to humoral and cellular hyperinflammation, associated with virus persistence and strong immunopathology causing TMA and ARDS. 
Figure 1. SARS-CoV-2 driven complement activation and potential targets of the complement cascade.

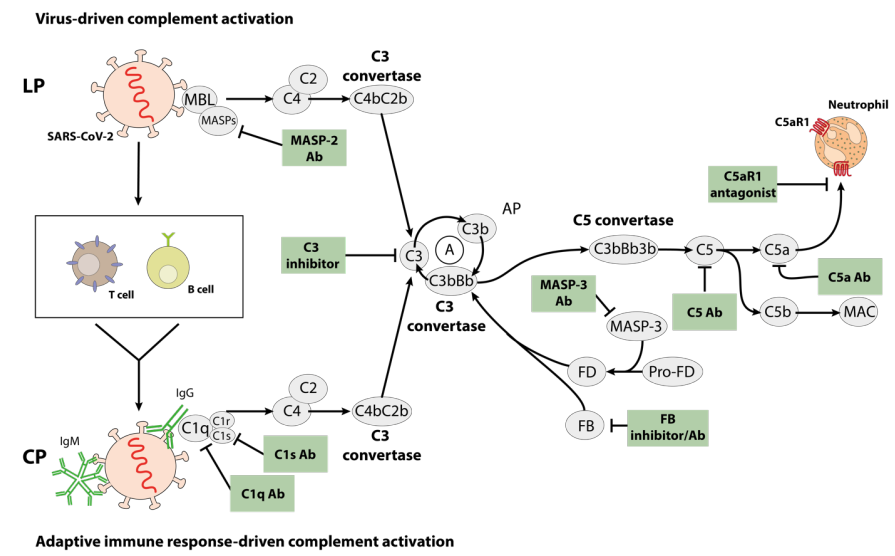


Figure 2. Complement effector functions leading to SARS-CoV-2-induced thrombotic microangiopathy (TMA) and acute lung injury.

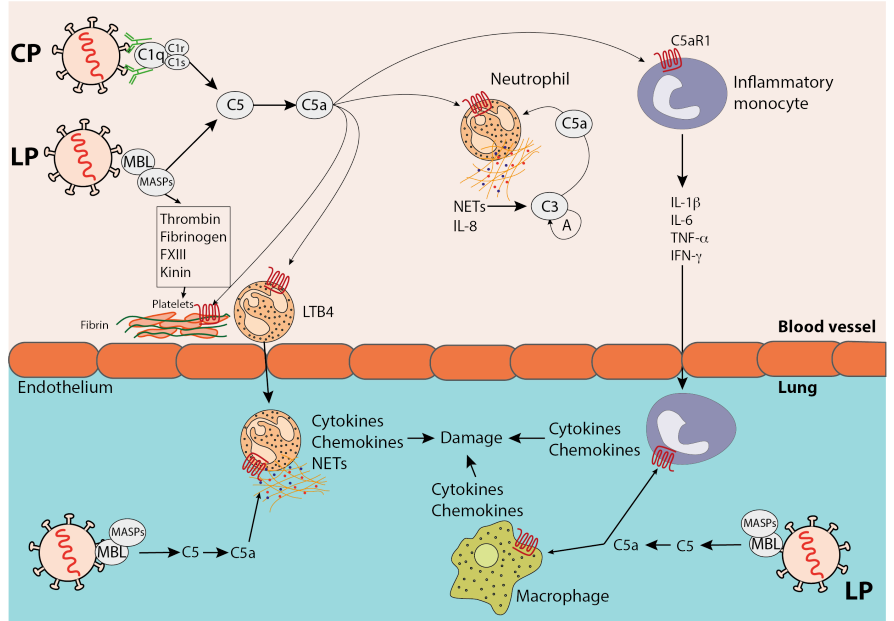


Figure 3. Impact of inherited gain- or loss-of function mutations in complement activator or regulator proteins on complement pathway activation.

A

Balanced complement-activation

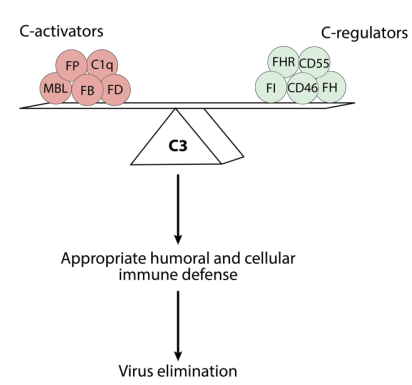

B

Complement overactivation

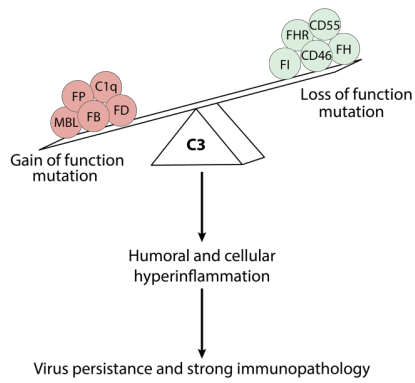

